\title{
Investigations of the surface chemistry of silicon substrates etched in a rf-biased inductively coupled fluorocarbon plasma using Fourier-transform infrared ellipsometry
}

\author{
Citation for published version (APA): \\ Kroesen, G. M. W., Lee, H-J., Moriguchi, H., Motomura, H., Shirafuji, T., \& Tachibana, K. (1998). Investigations \\ of the surface chemistry of silicon substrates etched in a rf-biased inductively coupled fluorocarbon plasma using \\ Fourier-transform infrared ellipsometry. Journal of Vacuum Science and Technology A: Vacuum, Surfaces, and \\ Films, 16(1), 225-232. https://doi.org/10.1116/1.580976
}

DOI:

$10.1116 / 1.580976$

Document status and date:

Published: 01/01/1998

\section{Document Version:}

Publisher's PDF, also known as Version of Record (includes final page, issue and volume numbers)

\section{Please check the document version of this publication:}

- A submitted manuscript is the version of the article upon submission and before peer-review. There can be important differences between the submitted version and the official published version of record. People interested in the research are advised to contact the author for the final version of the publication, or visit the DOI to the publisher's website.

- The final author version and the galley proof are versions of the publication after peer review.

- The final published version features the final layout of the paper including the volume, issue and page numbers.

Link to publication

\footnotetext{
General rights

- You may freely distribute the URL identifying the publication in the public portal. follow below link for the End User Agreement:

www.tue.nl/taverne

\section{Take down policy}

If you believe that this document breaches copyright please contact us at:

openaccess@tue.nl

providing details and we will investigate your claim.
}

Copyright and moral rights for the publications made accessible in the public portal are retained by the authors and/or other copyright owners and it is a condition of accessing publications that users recognise and abide by the legal requirements associated with these rights.

- Users may download and print one copy of any publication from the public portal for the purpose of private study or research.

- You may not further distribute the material or use it for any profit-making activity or commercial gain

If the publication is distributed under the terms of Article $25 \mathrm{fa}$ of the Dutch Copyright Act, indicated by the "Taverne" license above, please 


\title{
Investigations of the surface chemistry of silicon substrates etched in a rf-biased inductively coupled fluorocarbon plasma using Fourier- transform infrared ellipsometry
}

\author{
G. M. W. Kroesen, ${ }^{\text {a) }}$ Ho-Jun Lee, Hiroshi Moriguchi, and Hideki Motomura \\ Department of Electronic Science and Engineering, Kyoto University, Yoshida-Honmachi, Sakyo-Ku, \\ Kyoto 606, Japan \\ Tatsuru Shirafuji \\ Department of Electronics and Information Science, Kyoto Institute of Technology, Matsugasaki, Sakyo-Ku, \\ Kyoto 606 Japan \\ Kunihide Tachibana ${ }^{\text {b) }}$ \\ Department of Electronic Science and Engineering, Kyoto University, Yoshida-Honmachi, Sakyo-Ku, \\ Kyoto 606, Japan
}

(Received 12 April 1997; accepted 13 September 1997)

In situ Fourier-transform infrared (FTIR) ellipsometry has been performed on silicon substrates processed in a rf-biased transformer coupled plasma reactor. Plasmas in $\mathrm{CHF}_{3}, \mathrm{CF}_{4}, \mathrm{C}_{2} \mathrm{~F}_{6}$, and $\mathrm{C}_{4} \mathrm{~F}_{8}$ have been used. The reaction layer, which is present on the surface of the silicon wafer during the plasma process, has been analyzed in detail, addressing both chemical composition and thickness. The absolute reliability (expressed in terms of thickness) of the results is of the order of $0.01 \mathrm{~nm}$, which corresponds to $3 \%$ of a monolayer. The instabilities of a silicon surface, which have been observed under specific conditions, can be of the order of tens of percents of a monolayer, which clearly illustrates the advantage of using a real in situ technique like FTIR ellipsometry over quasi in situ techniques like x-ray photoemission spectroscopy and Auger electron spectroscopy. For $\mathrm{CHF}_{3}$ plasmas it has been found that, if the bias increases to moderate levels $(30-50 \mathrm{~V})$, the fluorocarbon film deposition rate decreases and the silicon etching reaction rate increases. The reaction layer changes from a thick, predominantly $\mathrm{CF}_{x}$ polymerlike film to a thin, carbon dominated layer of plasma and etching products showing vibrational absorptions of $\mathrm{SiF}_{x}, \mathrm{C}-\mathrm{C}$, and $\mathrm{CF}_{2}$. Increasing the bias voltage in a $\mathrm{CHF}_{3}$ plasma has a similar effect as increasing the $\mathrm{F} / \mathrm{C}$ ratio of the feed gas. (C) 1998 American Vacuum Society. [S0734-2101(98)04301-2]

\section{INTRODUCTION}

The continuous drive of the semiconductor manufacturing industry towards smaller feature dimensions (now going below $0.2 \mu \mathrm{m}$ ) and larger wafer sizes (now going to $30 \mathrm{~cm}$ diameter) has induced a corresponding development drive in the dry processing equipment manufacturing industry towards single wafer reactors operating at low pressure and high electron density. In all of those reactors the main plasma is generated in one (high density) zone, and the wafer chuck can be biased by a second, usually radio frequency, discharge. In this way the plasma density, which bears a correspondence to the ion flux to the substrate on the one hand, and the energy of the ions which bombard the silicon wafer surface on the other hand can be influenced independently. Many plasma source geometries have been introduced, e.g., electron cyclotron resonance reactors, helicon sources, helical resonator sources, cascade arc sources, and several different geometries of inductively coupled plasmas (ICP). Presently, the ICP geometries are gaining field because of their relatively uncomplicated operation properties.

\footnotetext{
${ }^{a}$ On leave from Department of Physics, Eindhoven University of Technology, P.O. Box 513, 5600 MB Eindhoven, The Netherlands.

b) Author to whom correspondence should be addressed; Electronic mail: tatibana@kuee.kyoto-u.ac.jp
}

Within the class of ICPs, the transformer coupled plasmas (TCP), which use a planar spiralized coil, show a good performance in terms of uniformity, profile control, and etch rate. Therefore in this study we have used the TCP geometry.

The increase in wafer size and the simultaneous decrease of feature size together cause the cost per processed wafer to increase dramatically. This puts very strong demands on the accuracy and reproducibility of the various processing steps. As a result, it has become necessary to obtain a detailed insight of the surface chemistry during plasma processing. Consequently, there is a need for in situ surface diagnostics which can diagnose the reaction layer which is present on the surface of the silicon wafer during the plasma process. The number of available, truly in situ, surface diagnostics is very limited. For ex situ or quasi in situ measurements, x-ray photoelectron spectroscopy (XPS) and Auger electron spectroscopy (AES) are used by an increasing number of laboratories. ${ }^{1-3}$ In most cases, after plasma extinction and pump down, the wafer is transported under UHV conditions from the plasma chamber to the analysis chamber. This method has a few drawbacks. Firstly, the wafer surface could change during the transportation. Secondly, XPS and AES yield data on the overall surface concentration of various species. Information on the thickness of the reaction layer and the specific density of the various chemical species in it 


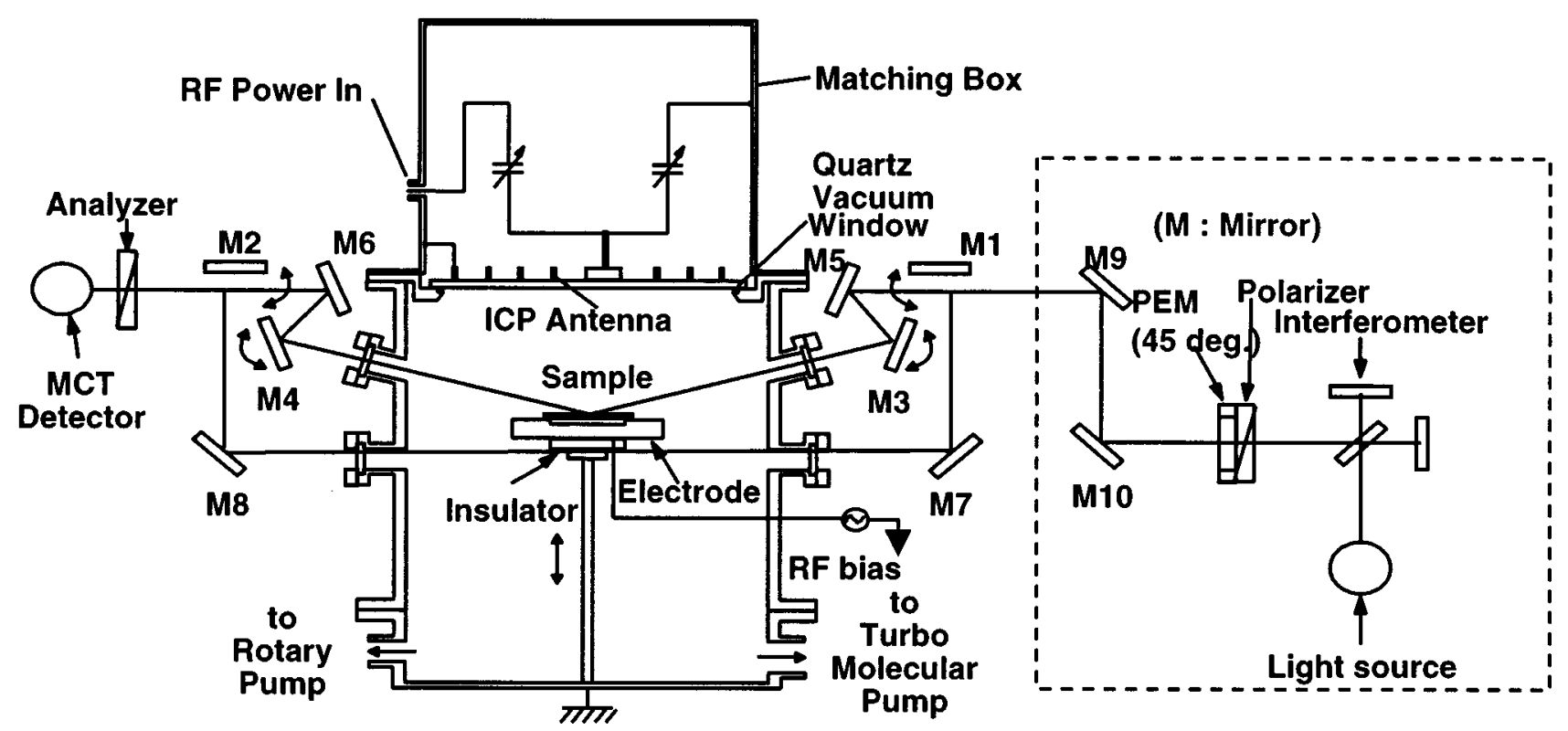

Chamber

FT-IR

FIG. 1. Schematic view of the experimental setup. Both the TCP reactor and the FTIR ellipsometer are outlined.

can only be extracted indirectly (e.g., by analyzing the transmission of the silicon bulk signal through the reaction layer) or by performing electron exit angle dependent measurements.

In this study we are using in situ spectroscopic infrared ellipsometry using a Fourier-transform infrared (FTIR) spectrometer (FTIR ellipsometry). In situ ellipsometry by itself is a technique which has found widespread use for many different applications and which can generate very detailed information. ${ }^{4}$ Also combined studies using in situ ellipsometry and quasi in situ XPS have been performed. ${ }^{5}$ If, however, in situ spectroscopic ellipsometry is performed in the infrared, specific, and quantitative chemical information which becomes available by studying the vibrational absorptions of the various bond groups present in the reaction layer can be obtained. Of course, conventional infrared absorption spectroscopy, either or not using attenuated total reflection yields similar chemical information, ${ }^{6}$ but quantitative information on both the thickness of the reaction layer and its chemical composition cannot be obtained. So far, FTIR ellipsometry has mainly been applied for studies of depositing plasmas. ${ }^{7}$ In a previous article, some of the authors of the present article have reported on the use of this technique for capacitively coupled etching plasmas. ${ }^{8}$ In this article we will discuss FTIR ellipsometry performed on silicon surfaces exposed to fluorocarbon plasmas in a rf-biased TCP plasma.

\section{EXPERIMENTAL SETUP}

Figure 1 shows a schematic representation of the experimental setup. The central part is the TCP reactor. The vessel is $260 \mathrm{~mm}$ in diameter and $385 \mathrm{~mm}$ in height. A planar, spiralized antenna is positioned over a quartz vacuum window. The outer diameter of the antenna is $165 \mathrm{~mm}$. The antenna is integrated in the matching network, which further comprises two vacuum capacitors. The radio frequency power is supplied by an ENI OEM-6 generator. For all experiments a power of $650 \mathrm{~W}$ has been used at a frequency of 13.56 MHz. On the other side of the quartz window the plasma is generated inductively. The wafer chuck can be translated vertically to allow for transmission gas phase absorption spectroscopy measurements as well as ellipsometry measurements. The gap between quartz window and biased wafer chuck is $115 \mathrm{~mm}$ in our typical ellipsometry measurements. For generating the bias, the power delivered by a RFPP LF-10 generator is fed to the electrode by means of a transformer coupled matching network. The generator can operate at frequencies in the range of $50-460 \mathrm{kHz}$, but for our experiments always $450 \mathrm{kHz}$ has been used. The gases are fed through STEC 400 MK3 mass flow controllers. Typically a flow of $10 \mathrm{sccm}$ has been used. The chamber is pumped by a Balzers Pfeiffer TPU 180 turbomolecular pump. The pumping speed is controlled by using an angular valve. For all experiments a gas pressure of 10 mTorr has been used. The primary pump is a single stage Alcatel rotary pump. The exhaust gases are cleaned in a dry scrubber. The (100) silicon wafers used were $n$-type doped, $3 \Omega \mathrm{cm}$. In general, square pieces of 5 by $5 \mathrm{~cm}$ were cut out of an 8 in. wafer. The wafers were single side polished in order to avoid internal reflections from the back side of the wafer. In general, immediately before being mounted on the wafer chuck, the wafers were dipped in HF and subsequently rinsed in deionized water. 
The FTIR-PMSE (phase modulated spectroscopic ellipsometry) setup and the measurement procedure has been described in detail elsewhere. ${ }^{9}$ In short the setup consists of a commercial FTIR spectrometer (JEOL JIR 7000), a wire grid polarizer, a photoelastic modulator (PEM, Hinds PEM-90), a wire grid analyzer, and a Graseby M16 midrange mercurycadmium-telluride (MCT) detector. $\mathrm{KBr}$ windows are mounted on the reaction chamber and aluminum folding mirrors are used to guide the beam from the light source to the sample and the MCT detector. The use of folding mirrors induces some systematic deviations of the primary ellipsometry data $\Psi$ and $\Delta$ because of the polarization induced by each reflection. However, as we will explain in the next section, the use of the optical density as primary measurement data eliminates these errors. The azymuth angles of the gridtype polaryzer and analyzer are set at $0^{\circ}$ and $45^{\circ}$ respectively. The modulation (phase retardation) frequency of the PEM is $37 \mathrm{kHz}$ and it is set at an azymuth angle of $45^{\circ}$. In order to obtain the ellipsometric parameters $\Psi$ and $\Delta$, the fundamental modulation frequency signal as well dc and second harmonic have to be measured. These signals are acquired using a lock-in amplifier (EG\&G 5209). Typically about 500 spectra are averaged. In this way a measurement, including all necessary calibrations, takes about $50 \mathrm{~min}$.

\section{DATA ANALYSIS}

In general, for most ellipsometry applications it is very common to use the ellipsometric angles $\Psi$ and $\Delta$. These angles depend on the complex ratio $\rho$ of the reflection coefficients $R_{p}$ and $R_{s}$ of the surface for light polarized in the $p$ and $s$ directions, respectively:

$$
\rho=\frac{R_{p}}{R_{s}}=\tan (\Psi) \exp (i \Delta) .
$$

For very thin films, however, it is more useful to use the optical density $D$ instead:

$$
D=-\log \left(\frac{\rho}{\rho_{\text {sub }}}\right)=\log \left(\frac{\tan \Psi_{\text {sub }}}{\tan \Psi}\right)-i\left(\Delta-\Delta_{\text {sub }}\right),
$$

where the quantities with a subscript suffix sub correspond to the values measured on the naked substrate and the unsuffixed quantities correspond to the values measured on the substrate with the thin film (in our case the reaction layer) on it. There are a few advantages associated with the use of the optical density. Firstly, it contains information on the thin film itself, the contributions to the spectra by the substrate are eliminated. Secondly, the deviations of the angles $\Psi$ and $\Delta$ which are induced by the folding mirrors, the nonideality of the polarizers and other effects are also cancelled out. ${ }^{9}$ The baseline of the optical density holds information on the thickness which can be easily extracted. As an illustration, in Fig. 2 the calculated real and imaginary parts of the optical density have been plotted as a function of wave number for four values of the film thickness. It is clear that an increasing film thickness results in a shifting and tilting baseline of the spectra of the real and imaginary parts of the optical density.

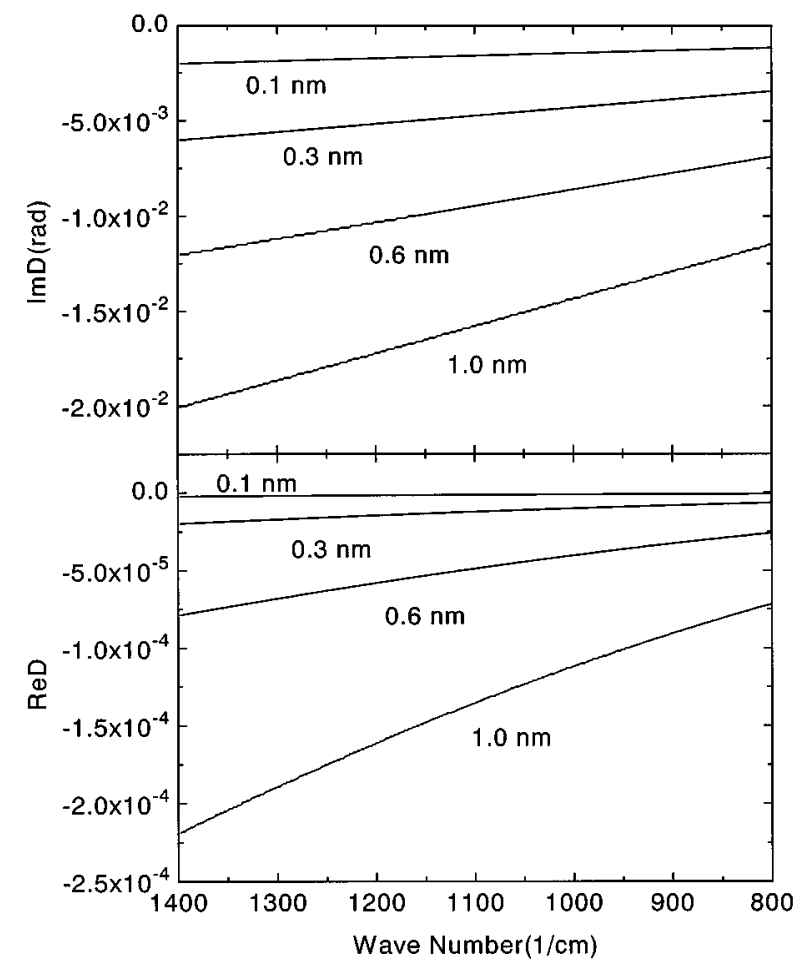

FIG. 2. Imaginary and real part of the optical density for various film thicknesses $(0.1,0.3,0.6$, and $1 \mathrm{~nm})$. The films were given a real dielectric constant of 2.4 .

The vibrational absorptions of the various chemical bonds or bond groups in the reaction layer have been modeled using the harmonic oscillator concept. For a given set of harmonic oscillators, the dielectric function $\epsilon$ is given by

$$
\epsilon(\sigma)=\epsilon_{\infty}+\sum_{j} \frac{F_{j}}{\sigma_{0 j}^{2}-\sigma^{2}+i \Gamma_{j} \sigma},
$$

where $\sigma$ is the wave number, $F$ is the strength of the mode (actually $F$ is the product of the oscillator strength and the volume density of the vibrating bond group), $\Gamma$ is the width of the Lorentzian absorption profile (which is associated with the damping of the vibration), $\epsilon_{\infty}$ is the background dielectric function (associated with the material density and its specific polarizability), and $\sigma_{0 j}$ is the central wave number. In our case, where the thin film under study is the reaction layer on a silicon surface processed in a fluorocarbon plasma, we expect spectra which consist of a set of many, partially overlapping, absorption peaks corresponding to the vibrations of $\mathrm{CF}_{x}$ and $\mathrm{SiF}_{x}$ groups, $\mathrm{Si}-\mathrm{C}$ and $\mathrm{C}-\mathrm{C}$ bonds, possibly $\mathrm{SiO}_{x}$ groups, etc. All the mentioned absorption peaks are located in the region from 800 to $1400 \mathrm{~cm}^{-1}$. Still it is possible to recognize the different vibrations. This is illustrated in Fig. 3 , where we plotted the simulated imaginary part of the optical density for two cases; only one absorption peak, and two overlapping peaks. Only the imaginary part of $D$ is given, because the presence of the second peak is most clearly shown there. One can see very clearly that the second peak can directly be detected, even with the naked eye. A further reason for using mainly the imaginary part of $D$ for 


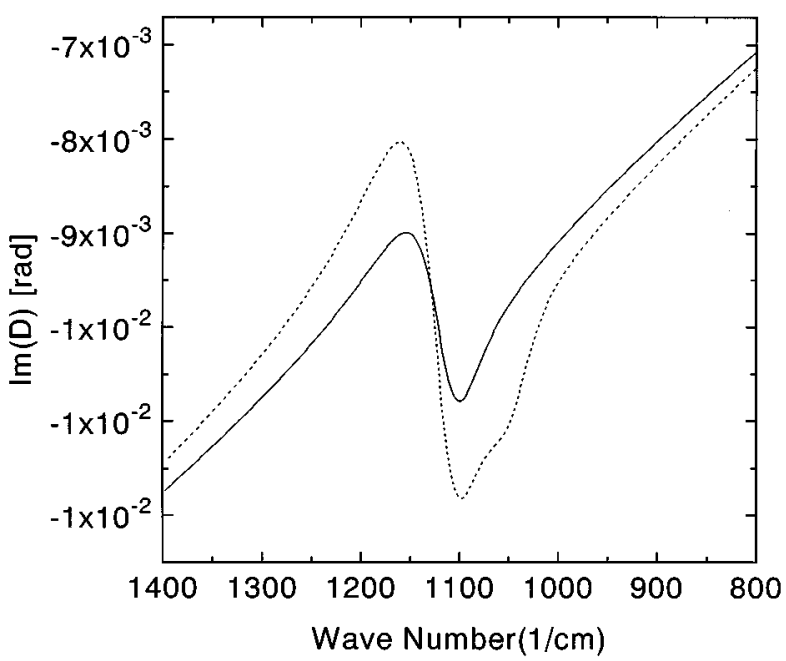

FIG. 3. Comparison of simulated spectra in the presence of only one vibrational absorption peak at $1100 \mathrm{~cm}^{-1}$ (full curve) or of two equally strong peaks, at $1100 \mathrm{~cm}^{-1}$ and at $1150 \mathrm{~cm}^{-1}$ (dashed curve). The width of both peaks is taken $80 \mathrm{~cm}^{-1}$, a value which is also found in the measurements. The film thickness is $1 \mathrm{~nm}$.

the analysis of the measurement data is that the signal-tonoise ratio of the imaginary part is much larger than that of the real part. ${ }^{9}$

In general, the measurements have been analyzed with a simulation program which is based on Eq. (3), taking into account the interference caused by multiple reflections of the light beam in the surface film. The program is able to handle up to eight vibrational absorptions. All simulation parameters like film thickness, peak location, strength and width, $\epsilon_{\infty}$, etc. are set by hand in a graphical menu environment. On the screen of the computer both measurement and simulation are given. Then the simulation parameters like film thickness and peak strength, width, and location are changed manually until there is sufficient agreement between measurement and simulation. Figure 4 presents a typical example of a measurement and the corresponding simulation. All of the available eight peaks were used to obtain a good fit in the spectral region $1300-800 \mathrm{~cm}^{-1}$. The agreement is quite good. One can see that in the region $1400-1300 \mathrm{~cm}^{-1}$ there still is a small disagreement between measurement and simulation. Apparently, eight peaks is not enough and more are needed.

If one wants to compare the results of the data analysis of FTIR ellipsometry spectra with the results obtained with, e.g., XPS, then the best way to represent the data is as the product of peak strength and film thickness. This product is proportional to the overall surface density like it is measured by XPS.

One more remark has to be made with respect to the interpretation of the results. This is related to the wafer preparation before mounting in the reactor. The HF dip and the rinse leave the silicon surface passivated with hydrogen: exactly one monolayer of hydrogen atoms is present on the wafer surface. This situation is used as a reference to take the

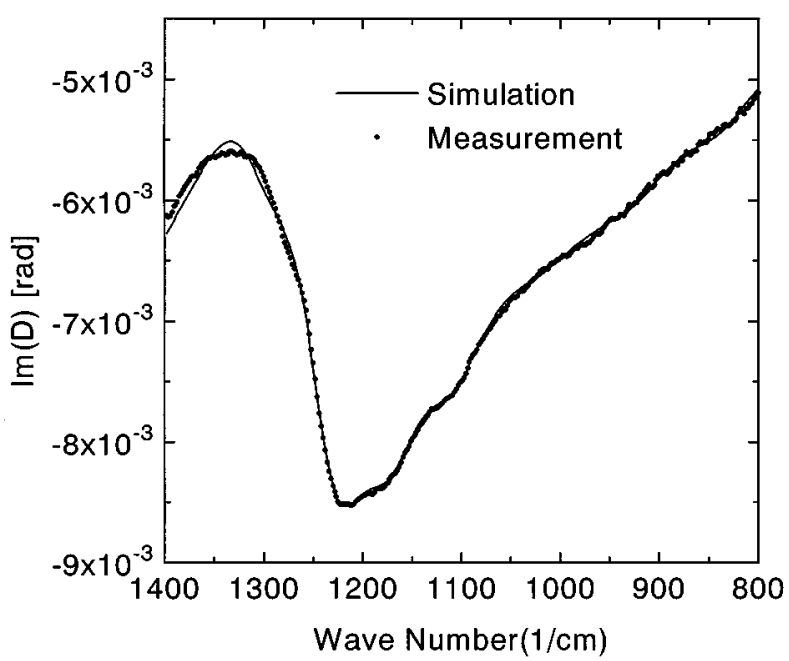

FIG. 4. Typical examples of simulated and measured spectra of the imaginary part of the optical density $D$.

$\rho_{\text {sub }}$ spectra as introduced in Eq. (2). When the plasma is switched on, this hydrogen layer is very quickly removed and replaced by the reaction layer. In principle, a situation with a perfectly clean silicon surface should have been used as a reference in order to obtain absolute and accurate values for the thickness of the reaction layer. However, a perfectly clean silicon surface is impossible to obtain. The hydrogen passivated situation is probably the next best solution. As a result of the presence of the hydrogen monolayer, however, the thickness which is obtained from the simulations will have an offset of roughly $0.15 \mathrm{~nm}$. All the results which will be presented in the next section have been corrected for this.

\section{RESULTS}

\section{A. Reproducibility, stability, and accuracy}

In order to test the reproducibility of the instrument, two measurements were performed on the same, stable, substrate (an untreated silicon wafer covered with its native oxide) which was placed on the wafer chuck in the evacuated plasma chamber. The second spectrum was taken about $1 \mathrm{~h}$ after the first one. The HF dip was deliberately not performed, because hydrogen covered silicon surface is not perfectly stable: exposing it to air, it will readily oxidize in approximately $30 \mathrm{~min}$, and even under vacuum conditions the surface may change. Of the two spectra collected, the first one was used as reference, the second one to calculate the optical density using Eq. (2). If the reproducibility of the instrument and the stability of the surface were perfect, then the result of the measurement would be a straight, horizontal line at $\operatorname{Im}(D)=0$. Any deviation of that line indicates either a changing surface (e.g., due to adsorption of species present in the vacuum chamber) or a measurement error. The change in the imaginary part of the optical density as displayed in Fig. 5 corresponds to an effective thickness of about 0.01 $\mathrm{nm}$. This corresponds to roughly $3 \%$ of monolayer. If the 


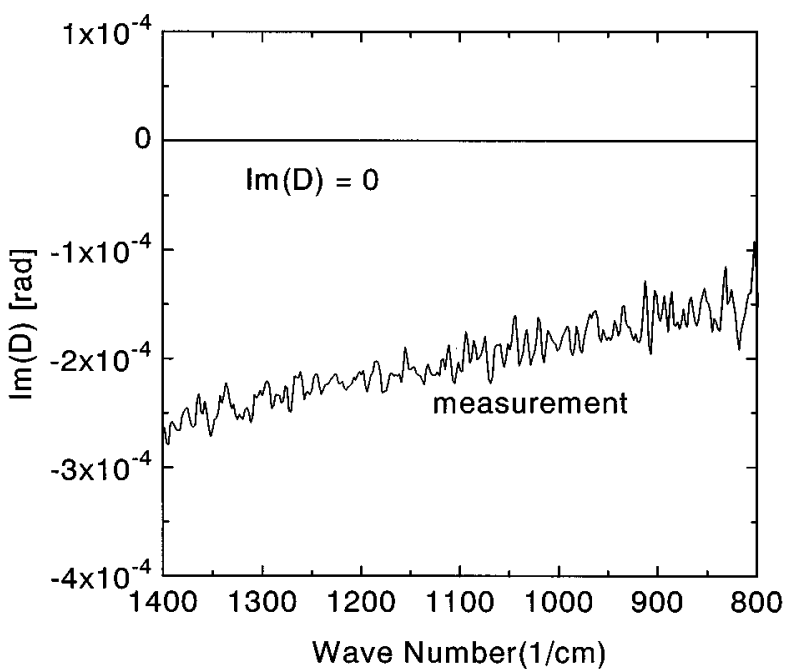

FIG. 5. Imaginary part of the optical density of a silicon surface covered with its native oxide. In between the acquisition of the reference and data spectra the wafer was not treated, it was just exposed to a vacuum of $10^{-6}$ Torr. The main purpose of this graph is to show the reproducibility of the instrument. With perfect reproducibility, the graph should be a straight horizontal line at $\operatorname{Im}(D)=0$. The magnitude of the measured $\operatorname{Im}(D)$ spectrum corresponds to an effective thickness of $0.01 \mathrm{~nm}$.

spectrum of $\operatorname{Im}(D)$ is calculated for $0.01 \mathrm{~nm}$ thick layer with a dielectric constant of 2.4, then the spectrum of Fig. 5 is reproduced very well. This indicates that the deviation from the $\operatorname{Im}(D)=0$ line is mainly the result of a slightly changing surface due to adsorption of a very small amount (3\% of a monolayer) of material supplied by the gas phase rather than a measurement instrument drift. Adsorptions of this order of magnitude are to be expected since the wafer is exposed to a vacuum of roughly $10^{-6}$ Torr. At these pressures the arrival rate of gas phase species at the surface is still of the order of one monolayer per second.

A good illustration of the instability (or rather: chemical activity) of HF-dipped silicon wafers is given in Fig. 6. For the measurements displayed here, the reactor has been preconditioned by running a $\mathrm{C}_{4} \mathrm{~F}_{8}$ plasma for some time. This results in a thick $\mathrm{CF}_{x}$ polymer coating on all internal surfaces of the reactor. The coating can be porous in some locations, which increases the specific surface area. The coating is known to outgas for quite some time. After preconditioning of the plasma chamber, the wafer is placed on the wafer chuck within 5 min after the HF dip and deionized water rinse, and the chamber is evacuated. The first spectrum was taken $15 \mathrm{~min}$ after the start of the pumpdown. Then data were taken $75,120,200$, and $340 \mathrm{~min}$ after the first spectrum. The optical density was computed with Eq. (2), using the first spectrum as a reference. These spectra are displayed in Fig. 6. From the shape of the curves it is clear that here also a thin layer is created at the surface. In this case, however, the thickness is much larger than in the case of the native oxide covered wafer in the clean reactor (Fig. 5). The thickness is roughly $0.03 \mathrm{~nm}$ after $75 \mathrm{~min}, 0.05 \mathrm{~nm}$ after 120 min, $0.04 \mathrm{~nm}$ after $200 \mathrm{~min}$, and $-0.04 \mathrm{~nm}$ (!) after $340 \mathrm{~min}$.

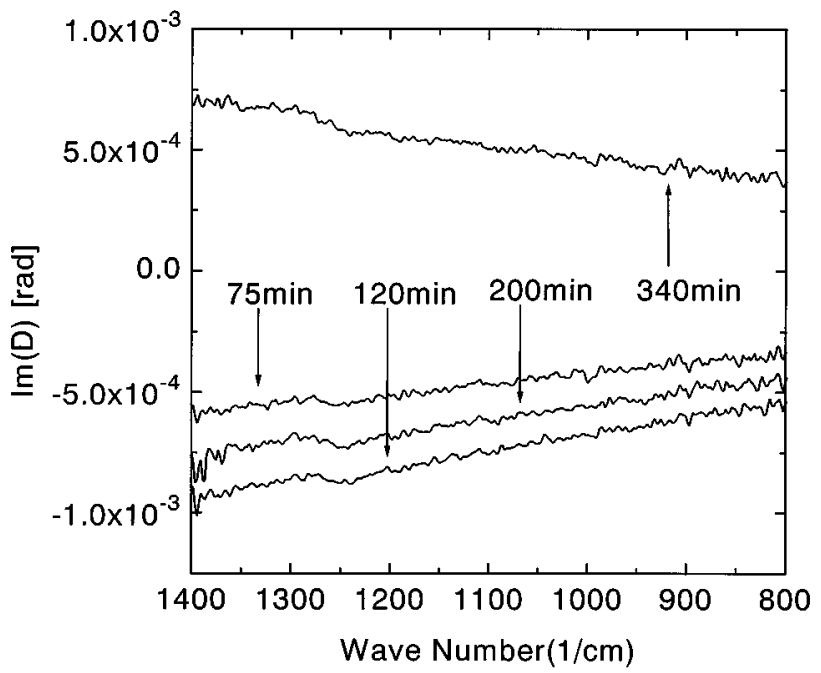

FIG. 6. Imaginary part of the optical density of a silicon surface. The wafer was dipped in HF, rinsed with deionized water, and inserted in the plasma chamber within 5 min after the HF dip. The first spectrum was taken 15 min after the start of the pumpdown. The data were taken 75, 120, 200, $340 \mathrm{~min}$ after the first spectrum. The optical density was computed with Eq. (2), using the first spectrum as a reference.

Whereas in Fig. 5 the signal-to-noise ratio does not allow the identification of vibrational absorptions, in Fig. 6 we can clearly see a vibrational adsorption at $1225 \mathrm{~cm}^{-1}$. As we will show in the next section, this location corresponds to vibrations of $\mathrm{CF}_{2}$ groups. The $\mathrm{CF}_{2}$ probably comes from the $\mathrm{CF}_{x}$ polymer covered walls of the preconditioned reactor. Simulations of the spectra indicate that the mode strength $F$ is the same for all spectra in this figure. The fact that the optical density which is computed using the first measurement as reference and the last measurement as data is larger than zero, indicates that actually the last spectrum, which was taken after a long pumpdown time, corresponds to the cleanest surface. Therefore actually the last spectrum should have been used as a reference. From the data the $\mathrm{CF}_{2}$ coverage of the surface can be extracted as a function of time after pump down start (see Fig. 7). Here we have assumed that after completion of the pumpdown procedure the $\mathrm{CF}_{2}$ coverage has decreased to zero. If that assumption is not justified, then the whole curve in Fig. 7 has shifted upwards with the amount of $\mathrm{CF}_{2}$ coverage at the end of the pump down procedure.

Apparently, immediately after the start of the pumpdown procedure, $\mathrm{CF}_{2}$ radicals desorb from the walls of the reactor and adsorb to the surface of the silicon wafer. As the pumpdown procedure proceeds and the pressure drops, the $\mathrm{CF}_{2}$ groups desorb again from the surface. Note that we are dealing with minute effects: the maximum $\mathrm{CF}_{2}$ coverage is about $30 \%$ of a monolayer. Still, these measurements clearly show the sensitivity of FTIR ellipsometry as an in situ surface diagnostic, and also they show that surfaces actually can change in a vacuum, depending on reactor wall conditions and base pressure. Regarding these aspects, FTIR ellipsometry is superior to quasi in situ XPS because it allows surface 


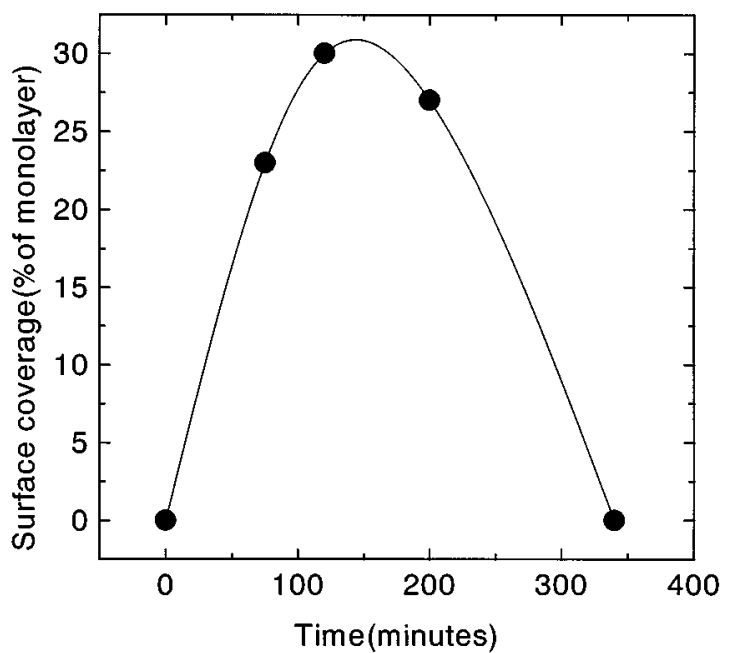

FIG. 7. The $\mathrm{CF}_{2}$ coverage (expressed as a percentage of a monolayer) of the HF-dipped silicon wafer surface as a function of time after the start of the pumpdown procedure.

characterization in the plasma chamber itself, without moving the sample to an UHV environment.

\section{B. Peak assignments}

The example spectrum given in Fig. 4 corresponds to a plasma in $\mathrm{CHF}_{3}$ with a rf bias voltage of $30 \mathrm{~V}$. The peaks which were used for the simulation are located at 1300 , 1225, 1170, 1104, 1025, 980, 926, and $838 \mathrm{~cm}^{-1}$. All peaks have a width of $80-90 \mathrm{~cm}^{-1}$, which is common for halogen containing bond groups. It is very difficult to detect the locations of the various adsorption peaks from the graph of $\operatorname{Im}(D)$ with the naked eye. This is partly due to the fact that absorptions do not show up in $\operatorname{Im}(D)$ as Lorentzian peaks but as dipsersionlike structures, of which also the shape changes with absorption strength. Therefore, careful comparison of simulated and measured results is the only way to get reliable data on the location, oscillator strengths, and widths of the various absorptions.

At higher bias voltages, the $838 \mathrm{~cm}^{-1}$ peak shifts to $878 \mathrm{~cm}^{-1}$, at $0 \mathrm{~V}$ bias it is not present at all. If $\mathrm{CF}_{4}$ and $\mathrm{C}_{2} \mathrm{~F}_{6}$ are used instead of $\mathrm{CHF}_{3}$ then the peaks at 1170 and $1104 \mathrm{~cm}^{-1}$ disappear. At higher bias voltages, an additional peak appears at $1138 \mathrm{~cm}^{-1}$. In two previous articles ${ }^{8,9}$ the regions around $1200,1030,890$, and $850 \mathrm{~cm}^{-1}$ were associated with $\mathrm{CF}_{x}, \mathrm{SiF}_{4}, \mathrm{SiF}$, and $\mathrm{SiF}_{2}$, respectively. We now propose a more detailed peak assignment, which is presented in Table I. The assignment of the $1300 \mathrm{~cm}^{-1}$ peak to CF is based on the proximity of the gas phase absorption bands of CF radicals. ${ }^{10}$ There is no disagreement on the assignment of the peak at 1225 to $\mathrm{CF}_{2}{ }^{8,9}$ Since the peaks at 1170 and $1104 \mathrm{~cm}^{-1}$ disappear in the case of nonhydrogen containing feed gases, we attribute them to hydrogen containing fluorocarbon groups. The analogy with the $\mathrm{CF} / \mathrm{CF}_{2}$ peak locations leads us to the detailed assignment of $1170 \mathrm{~cm}^{-1}$ to $\mathrm{CHF}$ and $1104 \mathrm{~cm}^{-1}$ to $\mathrm{CHF}_{2}$ (the wave number difference between $\mathrm{CF}$ and $\mathrm{CF}_{2}$ is $1300-1225=75 \mathrm{~cm}^{-1}$, and the wave number
TABLE I. Assignment of the vibrational absorption wave numbers to the various bond groups.

\begin{tabular}{cl}
\hline \hline Wave number $(1 / \mathrm{cm})$ & Bond group \\
\hline 1300 & $\mathrm{CF}$ \\
1225 & $\mathrm{CF}_{2}$ \\
1170 & $\mathrm{CHF}$ \\
1138 & $\mathrm{Si}-\mathrm{C}$ \\
1104 & $\mathrm{CHF}_{2}$ \\
1025 & $\mathrm{SiF}_{4}$ \\
980 & $\mathrm{C}-\mathrm{C}$ on $\mathrm{Si}$ surface \\
926 & $\mathrm{C}-\mathrm{C}$ in $\mathrm{CF}_{x}$ polymer \\
878 & $\mathrm{SiF}$ \\
838 & $\mathrm{SiF}_{2}$ \\
\hline
\end{tabular}

difference between the proposed $\mathrm{CHF}$ and $\mathrm{CHF}_{2}$ is $\left.1170-1104=65 \mathrm{~cm}^{-1}\right)$. For the peak at $1170 \mathrm{~cm}^{-1}$, our assignment to $\mathrm{CHF}$ is very close to the previously reported one. ${ }^{11}$ The peak at $1025 \mathrm{~cm}^{-1}$ is attributed to $\mathrm{SiF}_{4}{ }^{9}$ The region between 1000 and $900 \mathrm{~cm}^{-1}$ is attributed to $\mathrm{C}-\mathrm{C}$ vibrations. In amorphous hydrogenated carbon films these bonds are strong, ${ }^{12}$ and the $1160 \mathrm{~cm}^{-1}$ peak has in that case been attributed to $s p^{3} \mathrm{C}-\mathrm{C}$. We speculate that the vibrational frequency of the $\mathrm{C}-\mathrm{C}$ bond is shifted in our case because of the presence of the fluorine atoms, which are attached to the carbon atoms. From the rf-bias dependence of the mode strengths, we have tentatively deduced the differential assignment of $980 \mathrm{~cm}^{-1}$ to $\mathrm{C}-\mathrm{C}$ in very thin reaction layers, where the carbon atoms both are bound to the silicon surface, and of $926 \mathrm{~cm}^{-1}$ to $\mathrm{C}-\mathrm{C}$ in $\mathrm{CF}_{x}$ polymer films (see next section). The peak at $1138 \mathrm{~cm}^{-1}$ is attributed to $\mathrm{Si}-\mathrm{C}$ vibrations. In amorphous hydrogenated silicon carbide, peaks are found at similar locations. Finally, in agreement with previous papers ${ }^{8,9}$ and references therein ${ }^{13}$ we assign $838 \mathrm{~cm}^{-1}$ to $\mathrm{SiF}_{2}$ and 878 to $\mathrm{SiF}$.

\section{C. $\mathrm{CHF}_{3}$ plasmas and $\mathrm{rf}$ bias dependence}

For plasmas in $\mathrm{CHF}_{3}$, spectra have been taken for various values of the bias voltage after $30 \mathrm{~s}$ of plasma treatment. Each spectrum has been analyzed by fitting a simulated spectrum to the measurement using the procedure described in Sec. III. Then for each absorption peak, the product of the mode strength and the reaction layer thickness was computed (as explained earlier, this product is proportional to the overall surface density of the chemical bond groups involved). In Fig. 8 this product is plotted as a function of $\mathrm{rf}$ bias voltage for the $\mathrm{CF}, \mathrm{CF}_{2}, \mathrm{CHF}$, and $\mathrm{CHF}_{2}$ bond groups, as well as for the $\mathrm{C}-\mathrm{C}$ vibration in $\mathrm{CF}_{x}$ polymers. One sees clearly that the $\mathrm{CHF}$ and $\mathrm{CHF}_{2}$ vibrations show identical behavior. Furthermore, these H-containing groups are only present in the reaction layer for low bias voltages $(0$ and $30 \mathrm{~V})$. As soon as the bias voltage is $50 \mathrm{~V}$ or more, these groups disappear. This must be related to the small mass of the hydrogen atom: the sputter efficiency increases with smaller target atom mass. Apparently the hydrogen atoms are sputtered away from the surface reaction layer even at low bias voltages like $50 \mathrm{~V}$. One also clearly sees that the $\mathrm{C}-\mathrm{C}$ vibration (in $\mathrm{CF}_{x}$ 


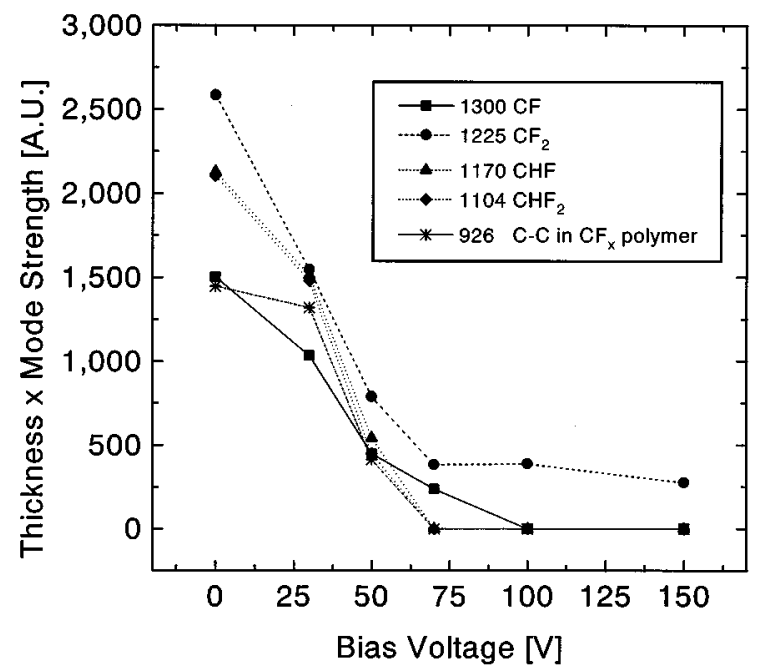

FIG. 8. Product of thickness and mode strength of the group vibrations of various $\mathrm{CH}_{x} \mathrm{~F}_{y}$ species and of $\mathrm{C}-\mathrm{C}$ bond (in $\mathrm{CF}_{x}$ polymer) vibrations as a function of rf bias voltage for a $\mathrm{CHF}_{3}$ plasma.

polymer) disappears at bias voltages of $70 \mathrm{~V}$ and more. At these higher voltages, the reaction layer is not polymerlike any more. The CF group is only present for low bias voltages; it disappears at bias voltages of $100 \mathrm{~V}$ and higher. The only fluorocarbon group which is still on the surface at high bias voltages is $\mathrm{CF}_{2}$. This is explained by the chemical stability of $\mathrm{CF}_{2}$, which is related to the closed electronic structure: all electrons are paired. For instance, it has been observed that gas phase $\mathrm{CF}_{2}$ radicals have a very long lifetime, which can go up to seconds. ${ }^{10}$

In Fig. 9 the product of reaction layer thickness and mode strength is plotted for the etching reaction related species $\mathrm{SiF}_{4}, \mathrm{C}-\mathrm{C}$ (at the silicon surface), $\mathrm{Si}-\mathrm{C}$ and $\mathrm{SiF}_{x}$ (for this last peak the two peaks at 838 and $878 \mathrm{~cm}^{-1}$ have been taken

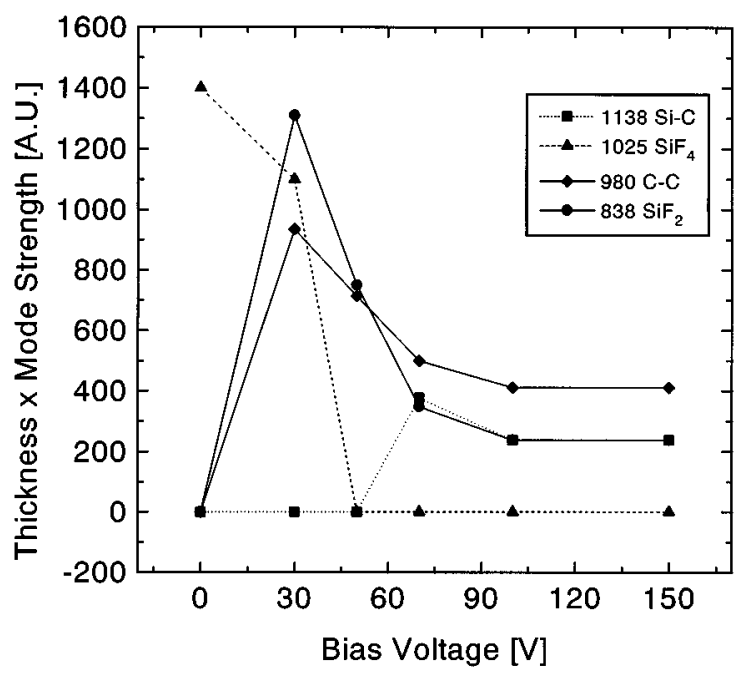

FIG. 9. Product of thickness and mode strength of $\mathrm{SiF}_{4}, \mathrm{C}-\mathrm{C}$ (at Si surface), $\mathrm{Si}-\mathrm{C}$, and $\mathrm{SiF}_{x}$ group vibrations as a function of $\mathrm{rf}$ bias voltage for a $\mathrm{CHF}_{3}$ plasma.

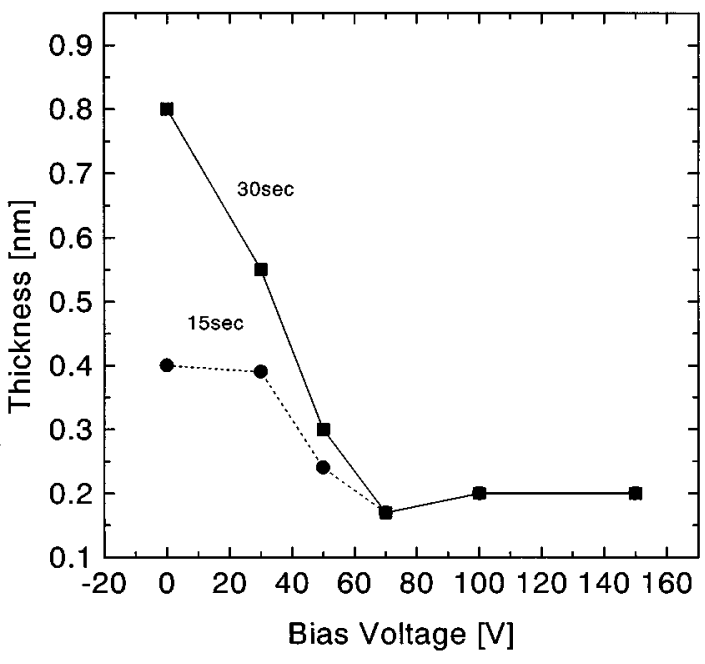

FIG. 10. Thickness of the reaction layer as a function of $\mathrm{rf}$ bias voltage for two plasma durations. The full curve corresponds to $30 \mathrm{~s}$ of plasma, the dotted curve to $15 \mathrm{~s}$.

together). $\mathrm{SiF}_{4}$ is only present in the reaction layer at low bias voltages. In order to test whether the $\mathrm{SiF}_{4}$ is adsorbed at the surface (i.e., prior to desorption) or whether it is distributed throughout the reaction layer thickness, the surface was exposed to a He plasma. He plasma treatment is performed for $1 \mathrm{~s}$ at the condition of pressure $30 \mathrm{mTorr}$, rf power 300 W. Plasma potential, electron density, and electron temperature are measured as $18 \mathrm{~V}, 1.3 \times 10^{10} / \mathrm{cm}^{3}$, and $4.17 \mathrm{eV}$, respectively. He atoms are very light, and they only can sputter atoms which are even lighter (i.e., hydrogen), but the bombardment of $\mathrm{He}$ ions will still cause adsorbed $\mathrm{SiF}_{4}$ molecules to desorb from the surface. The spectra before and after the He plasma treatment were identical, which implies that the $\mathrm{SiF}_{4}$ is distributed throughout the reaction layer. The $\mathrm{Si}-\mathrm{C}$ vibration only sets in at bias voltages over $50 \mathrm{~V}$. For lower biases the reaction layer is apparently not very strongly bound to the silicon surface: it is more a polymerlike film lying on the surface. For high voltages, the $\mathrm{Si}-\mathrm{C}$ vibration is always present. The $\mathrm{SiF}_{2}$ vibration sets in at low bias voltages $(30 \mathrm{~V})$, decreases by a factor of 2 when the bias is increased to $70 \mathrm{~V}$, and remains roughly constant for even higher voltages. The $\mathrm{C}-\mathrm{C}$ vibration shows a similar behavior.

In Fig. 10 the thickness of the reaction layer is plotted as a function of the rf bias voltage for two plasma treatment duration times: 15 and $30 \mathrm{~s}$. For bias voltages of $70 \mathrm{~V}$ and higher, the reaction layer thickness is of the order of one monolayer, and it is stable, i.e., it does not increase with plasma duration. From 70 to $100 \mathrm{~V}$ there is a small increase in reaction layer thickness. This we attribute to small-scale roughening of the surface by the ion bombardment. For $0 \mathrm{~V}$ bias the reaction layer thickness is proportional to the plasma duration. This implies that here we have continuous deposition of a $\mathrm{CF}_{x}$ polymer film. As the bias increases, the deposition rate decreases (less and less difference between 15 and $30 \mathrm{~s}$ of plasma treatment). 


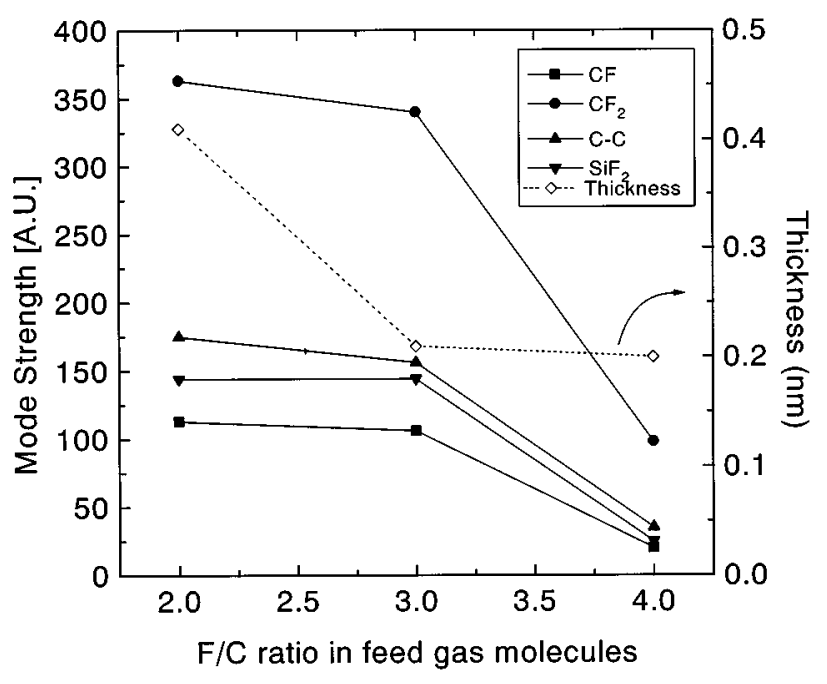

FIG. 11. Left axis: mode strength of the $\mathrm{CF}, \mathrm{CF}_{2}, \mathrm{SiF}_{2}$, and $\mathrm{C}-\mathrm{C}$ vibrations present in the reaction layer on a silicon wafer exposed to unbiased plasmas in $\mathrm{CF}_{4}, \mathrm{C}_{2} \mathrm{~F}_{6}$, and $\mathrm{C}_{4} \mathrm{~F}_{8}$ as a function of the $\mathrm{F} / \mathrm{C}$ ratio of the feed gas. Right axis: thickness of the reaction layer.

Putting all together, we arrive at the following general view of the reaction layer dynamics as a function of $\mathrm{rf}$ bias for $\mathrm{CHF}_{3}$ plasmas:

(1) Without $\mathrm{rf}$ bias, continuous deposition of a $\mathrm{CF}_{x}$ polymer film takes place.

(2) If the bias increases to moderate levels $(30-50 \mathrm{~V})$ then the deposition rate decreases and the etching reaction rate increases. The reaction layer changes from a thick, predominantly $\mathrm{CF}_{x}$ polymerlike film to a thin layer of plasma and etching products.

(3) For high biases (100 V and more) the reaction layer has a stable thickness of one monolayer, and only contains $\mathrm{SiF}_{x}, \mathrm{Si}-\mathrm{C}, \mathrm{C}-\mathrm{C}$, and $\mathrm{CF}_{2}$ groups.

\section{D. $C_{x} F_{y}$ plasmas: feed gas $C / F$ ratio dependence}

In order to study the dependence of the reaction layer composition and thickness on the $\mathrm{F} / \mathrm{C}$ ratio of the feed gas, experiments were done with plasmas in $\mathrm{CF}_{4}, \mathrm{C}_{2} \mathrm{~F}_{6}$, and $\mathrm{C}_{4} \mathrm{~F}_{8}$. All spectra at high bias voltages show results which are identical to the $\mathrm{CHF}_{3}$ case discussed in the previous paragraph. Apparently, high energy ion bombardment creates a reaction layer which is carbon rich, consisting of $\mathrm{Si}-\mathrm{C}$, $\mathrm{SiF}_{x}$, and $\mathrm{C}-\mathrm{C}$ bonds, regardless of the chemical composition of the fluorocarbon feed gas. At low bias, differences do occur. Figure 11 shows the mode strength of the $\mathrm{CF}, \mathrm{CF}_{2}$, $\mathrm{C}-\mathrm{C}$, and $\mathrm{SiF}_{2}$ bond groups (left axis and full curves). Also the thickness of the reaction layer is shown (right axis and dotted curve). If the $\mathrm{F} / \mathrm{C}$ ratio is high, then the reaction layer is thin (monolayer level) and it consists mainly of $\mathrm{CF}_{2}, \mathrm{C}-\mathrm{C}$, and $\mathrm{SiF}_{x}$. For lower $\mathrm{F} / \mathrm{C}$ ratios the thickness increases, all mode strengths increase (note: the relative distribution between the several vibrations remains more or less constant), and the $\mathrm{CF}$ vibrational absorption shows up. The increase of the mode strength with decreasing F/C ratio while maintain- ing the relative distribution over the several chemical bond groups means that there are less voids and/or roughness in the fluorocarbon layer. In general, decreasing the F/C ratio in the feed gas has an effect which is similar to decreasing the bias voltage in a $\mathrm{CHF}_{3}$ plasma: reactions favoring $\mathrm{CF}_{x}$ film deposition occur more frequently and reactions favoring the etching of the silicon surface occur less frequently.

\section{CONCLUSIONS}

We have shown that in situ FTIR ellipsometry provides a powerful means of characterizing the surface of a silicon wafer during plasma processing. The absolute reliability (expressed in terms of thickness) of the results is of the order of $0.01 \mathrm{~nm}$, which corresponds to $3 \%$ of a monolayer. The instabilities of a silicon surface, which have been observed under certain conditions, can be of the order of tens of percents of a monolayer, which clearly illustrates the advantage of using a real in situ technique like FTIR ellipsometry over quasi in situ techniques like XPS and AES. For $\mathrm{CHF}_{3}$ plasmas it has been found that, if the bias increases to moderate levels $(30-50 \mathrm{~V})$, the fluorocarbon film deposition rate decreases and the silicon etching reaction rate increases. The reaction layer changes from a thick, predominantly $\mathrm{CF}_{x}$ polymerlike film to a thin, carbon dominated layer with etching products showing vibrational absorptions of $\mathrm{SiF}_{x}, \mathrm{C}-\mathrm{C}$, and $\mathrm{CF}_{2}$. Increasing the bias voltage in a $\mathrm{CHF}_{3}$ plasma has a similar effect as increasing the F/C ratio of the feed gas.

\section{ACKNOWLEDGMENTS}

One of the authors, G. M. W. Kroesen, wishes to acknowledge the support of the Japanese Society for the Promotion of Science (JSPS), the Netherlands Organisation for Scientific Research (NWO), and the Netherlands Technology Foundation (STW).

${ }^{1}$ G. S. Oehrlein, P. J. Matsuo, M. F. Doemling, N. R. Rueger, B. E. E. Kastenmeier, M. Schaepkens, T. E. F. M. Standaert, and J. J. Beulens, Plasma Sources Sci. Technol. 5, 193 (1996).

${ }^{2}$ M. C. Piegnon, F. Clenet, and G. Turban, J. Electrochem. Soc. 143, 1347 (1996).

${ }^{3}$ R. D’Agostino, F. Fraeassi, C. Pacifino, and P. Capezzuto, J. Appl. Phys. 71, 462 (1992).

${ }^{4}$ G. M. W. Kroesen, G. S. Oehrlein, E. de Frsrt, and M. Haverlag, J. Appl. Phys. 73, 8017 (1993).

${ }^{5}$ G. S. Oehrlein, G. M. W. Kroesen, and J. L. Lindström J. Vac. Sci. Technol. 10, 3092 (1992).

${ }^{6}$ S. C. Deshmukh and E. S. Aydil, J. Vac. Sci. Technol. A 13, 2355 (1995).

${ }^{7}$ N. Blayo and B. Drevillon, Appl. Phys. Lett. 57, 786 (1990).

${ }^{8}$ T. Shirafuji, W. W. Stoffels, H. Moriguchi, and K. Tachibana, J. Vac. Sci. Technol. A 15, 209 (1997).

${ }^{9}$ K. Tachibana, T. Shirafuji, and S. Muraishi, Jpn. J. Appl. Phys., Part 135 , 3652 (1996).

${ }^{10}$ M. Haverlag, E. Stoffels, W. W. Stoffels, G. M. W. Kroesen, and F. J. de Hoog, J. Vac. Sci. Technol. A 12, 3102 (1994).

${ }^{11}$ M. E. Jacox and D. E. Milligan, J. Chem. Phys. 50, 3252 (1969).

${ }^{12}$ B. Dischler, R. E. Sah, P. Koidl, W. Fluhr, and A. Wokaun, Proceedings of the Seventh International Symposium on the Plasma of Chemistry, Einthoven, 1985 (IUPAC Subcommittee of Plasma Chemistry, Oxford, 1985), p. 45.

${ }^{13}$ V. M. Bermudez, J. Vac. Sci. Technol. A 10, 3478 (1992). 